\title{
O sujeito reconstruído: sobre algumas imagens mallarmaicas na obra de Alejandra Pizarnik
}

É provável que, desde Mallarmé, nenhum poeta digno de nota tenha negligenciado a busca da pureza poética da palavra, ou seja, tenha deixado de visar à eliminação dos resíduos semânticos impregnados no código por conta de sua funcionalidade comunicativa. É o caso de Alejandra Pizarnik, cujos dilemas tangenciam em muitos momentos as temáticas do mestre francês. Entretanto, que nuanças essas questões adquirem quando abordadas em uma poética surgida mais de meio século depois da morte do grande Simbolista?

Antes de refletir na poesia de Alejandra, convém o aprofundamento em alguns dos pontos mais relevantes da obra poético-filosófica de Mallarmé. Sua negação do sentido superficial das palavras, da carga semântica consagrada pelo uso, da banalização do signo linguístico acarreta uma empresa pela obtenção do valor original, quase mítico, da língua. Ao sonhar em vencer a barreira do arbitrarismo simbólico, ele buscava a camada anterior da nomeação, em que reside a Ideia, ou o Absoluto, ou tantos outros nomes possíveis. Trata-se do contato direto com o objeto, a natureza, sem qualquer intermediação poluidora. A partir daí, cabe ao poeta renomear o mundo exterior com uma linguagem absolutamente pura, livre dos dejetos comunicacionais, e criar seus próprios símbolos, metáforas, sintaxes. Ou - seria mais apropriado dizer - cabe a essa linguagem autocriar-se, emanar por si só essas novas associações. Tal estância do pensamento foi exaustivamente explorada por muitos pensadores do século XX, como Barthes (1971), que a denomina de "grau zero da escritura", ou Blanchot (1984), que afirma ser essa zona o local onde "as palavras sempre já desapareceram e esse movimento oscilante de aparecimento e desaparecimento".

Uma escrita que é gerada do bojo de seu significante, e que tem como matérias-primas recuperações etimológicas, associações sonoras, interposições gráficas e sugestões sensoriais, acaba por eliminar - simultaneamente - o social e o pessoal da poesia. Ou, pelo menos, aspira a ser desumanizada, a sair ilesa do crivo subjetivo de seu autor ou da interferência do repertório de seu fruidor. Faz disso sua utopia. Um dos precur-

\footnotetext{
* Mestre em Literatura e Crítica Literária pela PUC/SP e doutorando em Teoria da Literatura e Literatura Comparada pela Universidade de São Paulo (USP). Leciona Literatura Dramática na UNIBAN/ SP. E-mail: sergioguilherme@uol.com.br
} 
sores dessa interpretação da obra de Mallarmé (e de boa parte da lírica moderna), Hugo Friedrich explica que:

A lírica de Mallarmé encarna o isolamento total. Não sente necessidade alguma da tradição cristã, humanística, nem literária. Proíbe a si mesma qualquer intromissão do presente. Repele o leitor e se recusa a ser humana. (Friedrich, 1978, p. 139)

O que escapa ao crítico alemão (ou, pelo menos, é-lhe subdimensionado) é o contexto que deflagra esse radical fechamento no significante, de uma poesia "suprapessoal", para manter o vocábulo de Friedrich. Por que o sujeito, o "eu", teve seu sacrifício imposto por tal leva de poetas? O que jaz embaixo da aventura da forma?

Mallarmé, Rimbaud e outros ícones dessa busca viveram a grande explosão da vida moderna, industrial, que continha em si alguns fatores significantemente impactantes na cena social: a completa monetarização da economia; o distanciamento entre a Igreja e os aparelhos de poder; o crescimento da Imprensa; a democracia; enfim, uma revolução brusca no modo de vida absolutista e finalista reinante meio século antes. Alain Touraine (2002) defende que, em tal processo, o sujeito contraditoriamente afirma-se como soberano, mas perde parte de sua essência. Segundo o teórico, o poder de voto, a evolução científica e tecnológica e a ausência da subordinação teológica ofereceram a esse indivíduo um sem-número de opções. O destino já não era imposto, mas escolhido. A técnica cada vez mais apurada tornava as grandes cidades um produto humano, e não natural. As constituições surgidas em lugar da lei divina acentuavam essa nova responsabilidade. Subitamente, o mundo estava nas mãos do homem burguês. Paradoxalmente, porém, isso significou a perda de parte da identidade desse "eu", que se enfraqueceu conforme avançava seu narcisismo. O pensador francês defende que "o esgotamento da Modernidade transforma-se com rapidez em sentimento angustiante do semsentido" (Touraine, 2002, p. 101). É a angústia nietzschiana, o dilema dos personagens de Dostoiévski: o ser na Modernidade carece de valores, desestabilizando o sujeito. Não é de se espantar, portanto, que a Arte procure se afastar do humano, e nostalgicamente aspirar ao primitivismo de suas cores, volumes, sons e palavras.

Reduzo, aqui, ao máximo tais elaboradas teorias, por serem amplamente difundidas, e não constituírem o centro dessa breve análise. $O$ fato é que as premissas poéticas de Mallarmé encontram-se intrinsecamente ligadas ao cenário do auge burguês, ou seja, reagem à prevalência do sujeito na sociedade moderna. Porém, como a preocupação com a pureza da linguagem se manifesta na segunda metade do século, em particular na curta - mas elevada - obra de Alejandra Pizarnik? 
A produção da poeta argentina concentra-se em oito livros, escritos entre 1956 e 1971. Em seus primeiros livros, La última inocencia (1956) e Las aventuras perdidas (1958), ver Pizarnik (1994), os dilemas da juventude apresentam-se ainda diluídos em certa prolixidade. É como se seu verso ainda não tivesse logrado sublimar e adensar o sentido. Ainda assim, há passagens marcantes, em que a angústia que a seguiria por toda a vida já mostra as suas caras:

\section{CANTO}

el tiempo tiene miedo el miedo tiene tempo

el miedo

pasea por mi sangre

arranca mis mejores frutos

devasta mi lastimosa muralla

destrucción de destrucciones

sólo destrucción

y miedo

mucho miedo

miedo.

O vocabulário do poema transcrito é um apanhado dos temas expostos nas obras de juventude de Alejandra. O sangue, a destruição, a obscuridade, a noite, enfim, o sufocamento sentido diante do mundo exterior. Ficava clara, na apresentação da poeta, a sua inclinação para fechar-se em seu universo interno, explorar sua sensibilidade, indo na contramão das vanguardas argentinas que dominavam a cena poética argentina, como o movimento Poesía Buenos Aires, de Raúl Aguirre. Daí a sua importância histórica, pelo fato de ter ousado restituir a poesia ao lirismo individual em tempos de buscas formais e experiências estéticas. Isso leva o crítico Bernardo Koremblit a questionar: "Que poeta foi tão poeta de sua própria vida, além de sê-la em seus poemas, como Alejandra Pizarnik, conforme se deduz pelos temas que a ocuparam e a preocuparam com uma recorrência fiel, consciente, inexorável?" (Koremblit, 1991, p. 13-4) (tradução minha).

Tal volta ao eu-empírico não nasce, porém, de um mero diário confessional, mas resulta de um sofisticado processo de desconfiança de si própria e da natureza humana em geral. Ainda na primeira coletânea, a jovem nos brinda com um epigrama valoroso, espécie de reflexão seminal que desabrocharia nos próximos livros: 
Sérgio Bento

\author{
SÓLO UM NOMBRE \\ alejandra alejandra \\ debajo estoy yo \\ alejandra
}

Eis a insuficiência da palavra denunciada desde Mallarmé. O nome, símbolo arbitrário, não basta ao desejo de (auto)compreensão da poeta, que se coloca "abaixo" dele, e não inserida nele. A repetição cíclica, no poema, do nome-signo denota a sua banalização, o seu desgaste como moeda de troca, e consequente perda de valor. Graficamente, aliás, o eu aparece "emparedado", espremido entre os antropônimos. Sufocado pelo mundo das aparências e superficialidades, resta ao sujeito voltar a si: o solipsismo é o seu meio de sobrevivência.

Aprendiz confessa, Pizarnik explora diversas outras imagens mallarmaicas: o azul, o silêncio, o náufrago, o nada. Mas, em tal resgate, as metáforas parecem sempre voltar à figura da poeta mesma, em vez da autorreferencialidade que as palavras adquiriam no autor francês. Percebese, aqui, que embora tivesse herdado de Mallarmé essa busca da revisão poética das palavras, Alejandra distancia-se do mestre francês ao fazer do "eu" o seu principal substrato. Guardemos tal questão, porém, para depois. Antes, convém entender mais da poesia madura da autora argentina, que já na obra de 1962, Árbol de Diana, atinge a medida ideal de condensação e conquista o domínio do epigrama:

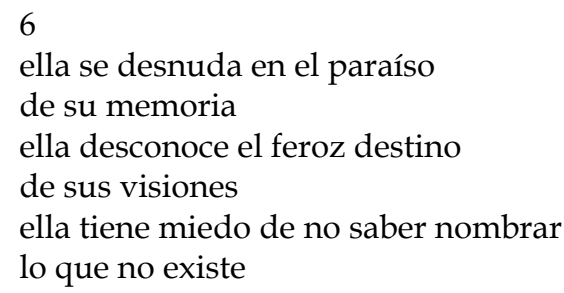

Mais uma vez, a questão do nomear, do poder que tem o poeta de criar as coisas por uma natureza quase encantatória da linguagem, parece ao eu-lírico mais um problema, um fardo, que um privilégio. As visões internas, inominadas, são mistérios que a fragilidade da língua não pode abarcar. Ao longo de todo esse belo livro, micro-poemas narram a angústia da não equivalência entre verdade e palavra, ora com pesar, ora com ironia, como no exemplo que se segue:

13

explicar con palabras de este mundo que partió de mí um barco llevándome 
A partir daí, até a sua morte, em 1972, Alejandra logrou estabelecer uma obra paradigmática na literatura argentina. Um sopro lírico entre os vanguardistas de 1950 e os "poetas guerrilheiros" de 1970, que se voltam contra a ditadura e transformam a poesia em panfleto.

Voltando à relação entre Mallarmé e Pizarnik, o poema "Nuit de coeur" ilustra como se dá a repaginação às metáforas do mestre francês:

Nuit de Coeur

Otoño en el azul de un muro: sé amparo de las pequeñas muertas.

Cada noche, en la duración de un grito, viene una sombra nueva. A solas danza la misteriosa autónoma. Comparto su miedo de animal muy joven en la primera noche de las cacerías.

O tom surrealista permite o surgimento de uma imagem quase mórbida, que funde elementos da natureza com expressões interiores, como o grito e o medo. A aparição de figuras femininas, como as mortas e a sombra autônoma, associada à ação de compartilhar o medo, faz supor que tais elementos sejam projeções do próprio eu-lírico, que se abre em dobradura a partir de imagens diversas. Todas elas, entretanto, deixam transparecer seu sentimento de fragilidade, desamparo. Assim, os elementos que surgem na poética de Alejandra sempre se voltam para dentro de si, a desvelar seu estado interior. Apesar de, mais uma vez, recuperar figuras mallarmaicas, como o azul e a sombra, não as desumaniza como o simbolista. Ao contrário, apossa-se dos objetos, transforma-os em sua extensão, multiplica-se por meio deles, metamorfoseia-se neles. Tudo vira matéria-prima para a expressão de sua angústia. É como nada se bastasse sem a presença onipotente do "eu" a lhe conferir a existência.

O que poderia explicar tal radical mudança no trato da palavra poética? Como se dá esse contraste na busca da pureza da palavra, desumanizada e autorreferente no berço do Modernismo e solipsista e narcísico na fase pós-moderna?

Como se viu, em Mallarmé a fuga do "eu" é uma recusa ao homem burguês, monádico que se formava no leito do Capitalismo industrial. A exploração de cores, aromas, imagens, palavras em sua matéria, em sua corporeidade, era uma forma de repelir a prevalência do indivíduo na sociedade moderna. Porém, tantas décadas depois, no período pós-guerras, como esse "eu" reagiu a mais de meio século de produção em massa, sociedade de consumo e globalização? O sujeito moderno, triunfo do Iluminismo, da democracia e da ciência, teria resistido com o mesmo vigor?

Ora, o cenário da segunda metade do século XX, em que Alejandra viveu, assistiu o desfecho trágico do homem monádico modernista, do 
burguês onipotente que conquistou o distanciamento religioso, o mercado de consumo e a democracia. O Capitalismo sofre, principalmente após o término da Segunda Guerra Mundial, um acelerado processo de virtualização, em que a produção industrial e o comércio perdem força para o capital financeiro. As facilidades de transporte e comunicação permitem a internacionalização (e o agigantamento) das corporações, que vão construindo, via propaganda, marcas globais fortíssimas. Além disso, a espetacularização da mídia, a proliferação das imagens e a inovação tecnológica avassaladora transformam tais décadas em tempos de grandes mudanças. Segundo David Harvey (1994), tal modelo econômico (que ele denomina "Acumulação flexível") acarreta um mundo efêmero, fugaz, em que há um imenso sentido de instabilidade. Com isso, a "obsolescência instantânea" faz com que tudo seja descartável, passageiro. Além disso, o bombardeio de estímulos sensoriais midiáticos afasta o contato diário com a natureza, com o mundo "real", e virtualiza a existência.

Diante de toda essa efervescência, o "eu" reage de forma a perder o sentido histórico de presente/passado/futuro. Ora, com a inconstância vigente, adota-se cada vez mais um estilo de vida episódico, em que diversos acontecimentos ocorrem paralelamente na vida do mesmo indivíduo. Não apenas a "narrativa do eu" (o termo é do teórico jamaicano Stuart Hall) se fragmenta, como o próprio "eu". A integralidade do sujeito torna-se irreal, impalpável:

Dentro de nós há identidades contraditórias, empurrando em diversas direções, de tal modo que nossas identificações estão sendo continuamente deslocadas (...) A identidade plenamente unificada, completa, segura e coerente é uma fantasia. (Hall, 2004, p. 13)

Voltando para a análise da obra de Alejandra Piarnik, convém citar um interessante trecho de Bernardo Koremblit, em que ele descreve o "eupoético" da poeta: "Alejandra Pizarnik abriga suas numerosas almas, e ela mesma é o asilo de suas sensações múltiplas e dos múltiplos de suas figurações, ela mesma é o abrigo em que se amparam os matizes de seu ser e as fases de sua obra." (Koremblit, 1991, p. 39) (tradução minha).

Mesmo sem citar os estudos do sujeito contemporâneo, o crítico teve a sensibilidade de notar essa fratura no sujeito poético que emana dos poemas de Alejandra. Transcrevo uma dessas peças em que a autora deixa vazar sua multiplicidade interna:

\author{
Invocaciones \\ Insiste en tu abrazo, \\ Redobla tu furia \\ Crea un espacio de injurias
}


Entre yo y el espejo

Crea un canto de leprosa

Entre yo y la que me creo

A projeção imagética do espelho é posta em paralelismo sintático (e semântico) com la que me creo, momento em que se dá a fratura. A incerteza da poeta acerca de seu ser corrobora a tese de Hall. A banalização das imagens interfere na própria percepção, deixa o sujeito contemporâneo em dúvida sobre sua própria identidade. No poema em questão, a forte imagem da leprosa denota um ser em decomposição.

Outro respeitado estudioso acerca desse novo homem é Christopher Lasch, que elege Narciso como o símbolo de tal identidade. Fatores como a Guerra Fria - cuja natureza psicológica exigia um constante estado de atenção -, agudas crises econômicas e crescente instabilidade política em diversos pontos do planeta levam o ser humano a um estado de sobrevivência, cujos símbolos maiores são os movimentos pacifistas e a contracultura. Embora estes ainda guardem um sentido coletivo, de forma geral o objetivo de continuidade de vida frente a um perigo iminente acentua o individualismo, ou a "mentalidade sitiada" que cita Lasch. Algumas de suas características marcantes são: a ironia como forma de autodefesa; o não comprometimento emocional com o mundo; e a constante sensação de impotência. O teórico adverte, entretanto, que a figura de Narciso não deve sugerir um egoísmo premeditado ou negativo.

as condições sociais vigentes, especialmente as fantásticas imagens da produção de massas que formam as nossas concepções de mundo, não somente encorajam uma contração defensiva do eu como colaboram para apagar as fronteiras entre o indivíduo e seu meio. Como nos lembra a lenda grega, é esta confusão entre o eu e o não-eu - e não o "egoísmo" - que distingue o apuro de Narciso. O eu mínimo ou narcisista é, antes de tudo, um eu inseguro de seus próprios limites, que ora almeja reconstruir o mundo à sua própria imagem, ora anseia fundir-se em seu ambiente numa extasiada união. (Lasch, 1986, p. 12)

Novamente recorro à sensibilidade do crítico Koremblit, que capta em Alejandra tal característica: “Alejandra Pizarnik (...) como se declarasse ilusória e nula toda a realidade independente ou separada de seu ser, somente aceita e reconhece como válidos e ontologicamente coexistentes a ela o ato e a ideia por ela experimentados" (Koremblit, 1991, p. 101-2) (tradução minha).

Creio, pois, que fica clara a intenção desse trabalho: a constante remissão de Alejandra Pizarnik às metáforas de Mallarmé representa uma retomada de tais imagens em uma abordagem radicalmente diferente. Em 
vez da despersonificação empreendida pelo Simbolista, a poeta argentina rearranja sua linguagem em torno de si, como que se fechando no seu mundo e repelindo qualquer objeto externo. Com isso tenta, via poesia, reencontrar sua integralidade, sua identidade. Sua busca pela pureza vocabular e sua concisão epigramática visam a eliminar o ranço social impregnado nas palavras, mas não mais em uma empreitada mítica que visava à primitividade lexical - como seu mestre francês -, mas em uma tentativa de descobrir o seu eu primevo, a sua plena consciência identitária. Poesia de fratura com o mundo a fim de soldar os seus próprios estilhaços internos; autorreconciliação via linguagem, eis a obra de Alejandra Pizarnik.

\section{Referencias bibliográficas}

BARTHES, Roland (1971). O grau zero da escritura. São Paulo: Cultrix, p. 53-72, 89-93.

BLANCHOT, Maurice (1984). O livro por vir. 13. ed. Lisboa: Relógio D’Água. FRIEDRICH, Hugo (1978). Estrutura da lírica moderna. São Paulo: Duas Cidades.

HARVEY, David (1994). Condição pós-moderna: uma pesquisa sobre as origens da mudança cultural. 4. ed. São Paulo: Loyola.

HALL, Stuart (2004). A identidade cultural na pós-modernidade. 9. ed. Rio de Janeiro: DP\&A.

LASCH, Christopher (1986). O mínimo eu: sobrevivência psíquica em tempos difíceis. São Paulo: Brasiliense.

KOREMBLIT, Bernardo Ezequiel (1991). Todas las que ella era: ensayo sobre Alejandra Pizarnik. Buenos Aires: Corregidor.

PIZARNIK, Alejandra (1994). Obras completas: poesía completa y prosa selecta. Buenos Aires: Corregidor.

TOURAINE, Alan (2002). Crítica da modernidade. 7. ed. Petrópolis: Vozes.

Recebido em maio de 2011.

Aprovado em julho de 2011.

\section{resumolabstract}

O sujeito reconstruído: sobre algumas imagens mallarmaicas na obra de Alejandra Pizarnik

Sérgio Bento

A leitura da obra poética da argentina Alejandra Pizarnik revela ao leitor atento um emaranhado de imagens que remetem a um dos ícones da poesia moderna, 
o francês Stéphane Mallarmé. Entretanto, nota-se, ao mesmo tempo, uma radical mudança de comportamento do sujeito poético da autora, que em vez de desaparecer no teatro autorreferente do significante - como na obra mallarmaica -, infla-se e transforma o mundo externo em sua extensão. O que tal artigo sustenta é que esse movimento se dá em resposta ao enfraquecimento e à fragmentação que caracterizam o dito sujeito contemporâneo.

Palavras-chave: Stéphane Mallarmé, Alejandra Pizarnik, sujeito contemporâneo

The subject reconstructed: about some mallarmaic images on the work of Alejandra Pizarnik

Sérgio Bento

The analysis of Alejandra Pizarnik's poetry displays (to an attentive reader) a tangle of images that refer to one of the icons of Modern Poetry, the french writer Stéphane Mallarmé. However, it is noted, simultaneously, an extreme shift in the behavior of the poetic subject of the Argentinian writer, who - instead of vanishing in the self-referent significant theater - as in Mallarmé's -, gets inflated and turns the external world into her extension. What this article defends is that such action happens as a feedback to the weakening and fragmentation processes that afflict the so-called contemporary self.

Key words: Stéphane Mallarmé, Alejandra Pizarnik, contemporary self

Sérgio Bento - "O sujeito reconstruído: sobre algumas imagens mallarmaicas na obra de Alejandra Pizarnik". Estudos de Literatura Brasileira Contemporânea, n. 38. Brasília, julho-dezembro de 2011, p. 173-181. 